\title{
The insulin-melatonin antagonism: studies in the LEW.1AR1-iddm rat (an animal model of human type 1 diabetes mellitus)
}

\author{
E. Peschke • K. Hofmann • I. Bähr • S. Streck • \\ E. Albrecht $\cdot$ D. Wedekind $\cdot$ E. Mühlbauer
}

Received: 22 November 2010 / Accepted: 14 March 2011 /Published online: 15 April 2011

(C) Springer-Verlag 2011

\begin{abstract}
Aims/hypothesis It is well documented that melatonin influences insulin secretion mediated by G-protein-coupled melatonin receptor isoforms MT1 and MT2, which are present in rat and human pancreatic islets, as well as in rat insulinoma cells. Recent investigations have proven that hyperinsulinaemic Goto-Kakizaki (GK) rats, which are a rat model of type 2 diabetic rats, and humans have decreased melatonin plasma levels, whereas a streptozotocin-induced rat model of diabetes developed reduced insulin levels combined with increased melatonin levels.

Methods Plasma levels of glucose, insulin and melatonin as well as RNA expression of pineal Aanat, Hiomt (also known as $A s m t$ ), insulin receptor, adrenoceptor $\beta 1$ and the clock genes Perl and Bmall (also known as Arntl) were determined in male and female LEW.1AR1-iddm rats as well as in insulin-substituted LEW.1AR1-iddm rats.
\end{abstract}

E. Peschke and K. Hofmann contributed equally to this study.

Electronic supplementary material The online version of this article (doi:10.1007/s00125-011-2138-0) contains supplementary material, which is available to authorised users.

E. Peschke $(\bowtie) \cdot$ K. Hofmann $\cdot$ I. Bähr $\cdot$ S. Streck $\cdot$ E. Albrecht Institute of Anatomy and Cell Biology,

Martin Luther University Halle-Wittenberg,

Grosse Steinstrasse 52,

06097 Halle, Germany

e-mail: elmar.peschke@medizin.uni-halle.de

D. Wedekind

Institute of Laboratory Animal Science,

Hannover Medical School Hannover,

Hannover, Germany

E. Mühlbauer

Saxon Academy of Sciences Leipzig,

Leipzig, Germany
Results Severe hypoinsulinaemia in diabetic LEW.1AR1$i d d m$ rats was associated with decreased body weight and increased melatonin plasma levels combined with mainly elevated expression of Aanat, Hiomt, pineal insulin receptor and adrenoceptor $\beta 1$. The changes were normalised by insulin substitution. Diurnal profiles of plasma melatonin and of antagonistic clock genes Perl and Bmall were maintained in diabetic and insulin-substituted rats.

Conclusions/interpretation The assumed causal relation between elevated melatonin and reduced insulin levels in LEW.1AR1-iddm rats is supported by the observation that insulin substitution normalised these changes. Further support for this interpretation comes from the observation that in GK rats an increase of plasma insulin was combined with a decrease of plasma noradrenaline (norepinephrine), the most important activator of melatonin synthesis. These relationships between the noradrenergic and insulin pathway support the existence of melatonin-insulin antagonism.

Keywords AA-NAT - Adrenoceptors · Circadian expression . Clock genes Perl and Bmall - Glucose · HIOMT - Insulin . Insulin receptor $\cdot$ Melatonin $\cdot$ Type 1 diabetes

$\begin{array}{ll}\text { Abbreviations } \\ \text { GK } & \text { Goto-Kakizaki } \\ \text { INS1 } & \text { Rat insulinoma beta cell line } \\ \text { IP }_{3} & \text { Inositol-1,4,5-triphosphate } \\ \text { MT1, MT2 } & \text { Melatonin receptor isoforms }\end{array}$

\section{Introduction}

Previous investigations have shown that melatonin inhibits glucose- and potassium chloride-stimulated insulin secre- 
tion from pancreatic islets as well as from rat insulinoma beta cell line (INS1) cells via a direct effect on the beta cell, which occurs in a concentration-dependent manner [1-3]. It is generally accepted that, in addition to nuclear and cytosolic binding sites, melatonin exerts its biological effects through specific, high-affinity, pertussis toxinsensitive, $G_{i}$ protein-coupled, seven-transmembrane melatonin receptor isoforms $\mathrm{MT}_{1}$ and $\mathrm{MT}_{2}[4,5]$. This is also true of pancreas, islets and pancreatic beta cells (INS1 cells) of rats [2, 6-9], as well as of the pancreas and pancreatic islets from humans $[10,11]$. Recently, it became possible to identify the intracellular signal cascades of pancreatic beta cells that are melatonin-dependent. Our own previous investigations have shown that the $\mathrm{MT}_{1}$ and $\mathrm{MT}_{2}$ receptors of pancreatic beta cells are linked to adenylate cyclasecAMP [2], the phospholipase C inositol-1,4,5-triphosphate $\left(\mathrm{IP}_{3}\right)[12,13]$ and the guanylate cyclase-cGMP pathways $[14,15]$. It was confirmed that melatonin inhibits the cAMP and cGMP pathways and consequently decreases insulin release $[2,8,14,15]$. In addition, the effects of melatonin are mediated by $\mathrm{G}_{\mathrm{q}}$-proteins, phospholipase $\mathrm{C}$ and the second messenger $\mathrm{IP}_{3}$, which mobilises $\mathrm{Ca}^{2+}$ from intracellular stores, resulting in increase of insulin $[12,13]$. In this context, recent investigations have analysed the plasma levels of melatonin in slightly hyperinsulinaemic GotoKakizaki (GK) rats, a rat model of type 2 diabetes [16], as well as in a hypoinsulinaemic streptozotocin-induced rat model of type 1 diabetes. GK rats had reduced plasma melatonin levels, whereas these were increased in streptozotocin rats [17-19]. Furthermore, it was proved that the reduced plasma melatonin levels were coupled with decreased pineal melatonin synthesis in GK rats $[18,20]$. On the other hand, the high melatonin plasma levels in streptozotocin rats were associated with increased expression of Aanat mRNA [21]. These results are in agreement with observations that administration of melatonin [22-27] or pinealectomy [28, 29] affect metabolic disturbances related to plasma insulin and diabetes [19]. Using the LEW.1AR1-iddm rat, we analysed the situation in a spontaneous animal model of human type 1 diabetes. We also investigated the effect of insulin substitution on melatonin levels, thereby confirming the existence of melatonin-insulin antagonism.

\section{Methods}

Animals The LEW.1AR1-iddm rat is an animal model of human type 1 diabetes with a fully competent immune system [30]. Disease manifestation occurs around day 60 of life. After a short pre-diabetic phase, beta cells in the immune cell-infiltrated pancreatic islets are quickly destroyed, resulting in a stable hypoinsulinaemic state
[30]. For our experiments, normoglycaemic LEW.1AR1 rats (controls), LEW.1AR1-iddm rats (diabetic) and LEW.1AR1-iddm rats treated for 10 days with implanted insulin-pellets (diabetic + insulin) (Linplant sustained release insulin implants; LinShin, Toronto, ON, Canada) were used. It was impossible to set up a sham-operated group lasting for 10 days, as the animals die within 2 3 days without insulin substitution. In addition, such an experiment without insulin substitution would not have been approved by the local Ethics Committee due to violations of animal welfare regulations. The rats were caged in groups of three animals and subjected to a $12 \mathrm{~h}$ light-dark cycle (light on at 07.00 hours) with a controlled temperature of $22 \pm 1^{\circ} \mathrm{C}$ and a humidity of $50-60 \%$. Rats were fed a standard diet (Altromin 1314; Altromin, Lage, Germany) and had free access to food and water.

Chemicals All chemicals were purchased from Sigma Chemicals (St Louis, MO, USA).

Groups and design of work The animal groups consisted of: (1) 75 male and 55 female normoglycaemic rats (controls); (2) 75 male and 55 female hyperglycaemic rats (diabetic); and (3) 50 male and 50 female insulinsubstituted diabetic rats (diabetic + insulin). The last group had insulin pellets implanted under the skin of the neck shortly after the onset of diabetes. The implants, which (according to the supplier) release about $2 \mathrm{U}$ of insulin per $24 \mathrm{~h}$ for up to 40 days were split into halves before implantation, thus half of the dose was applied per animal. The rats became diabetic about day 60 of their life and were killed immediately thereafter (except insulin-substituted animals). Age- and sex-matched control animals served as controls for the diabetic groups. Rats with insulin implants (diabetic+insulin) were killed around day 70 of their life, i.e. about 10 days after implantation at time of diabetes manifestation. For the sampling of a circadian series, animals of both sexes from the three cohorts were killed at $3 \mathrm{~h}$ intervals, with blood and tissue of at least five randomly chosen animals collected per time-point. For daytime-dependent examinations, killing and tissue sampling was performed by heart ventricle puncture while under deep anaesthesia. For peripheral blood glucose determination, blood of the tail vein was measured. Insulin and melatonin concentrations were determined in the blood plasma collected by heart ventricle puncture. Tissue sampling was continued under red light during the dark phase. Pineal glands were removed immediately, snapfrozen in liquid nitrogen after removal from the skull cavity and stored at $-80^{\circ} \mathrm{C}$. Animal experiments were performed according to German animal welfare regulations (permission number 2-737 MLU of the Landesverwaltungsamt Sachsen-Anhalt, Germany). 
Serum analyses The plasma levels of rats were investigated with regard to diurnal variations of glucose, insulin and melatonin. Blood glucose was analysed with a glucometer (MediSense Precision Xtra, Abbott Diagnostics, Wiesbaden, Germany), which functions on the basis of an enzyme-amperometrical principle. In both cases, the coefficients of correlation for comparison with the hexokinase and glucose dehydrogenase methods were 0.998. Insulin and melatonin levels were analysed by RIA using commercial kits. The insulin kit (Coat-ACount; Diagnostic Products, Biermann, Bad Nauheim, Germany) is based on a competitive hard-phase RIA for quantitative analysis of serum insulin. The RIA kit for measurement of melatonin levels (Melatonin rat RIA; Labor Diagnostika Nord LDN, Nordhorn, Germany) required $50 \mu \mathrm{l}$ blood plasma. Standards were within the range of $51-17,220 \mathrm{pmol} / \mathrm{l}$; the sensitivity limit of the assay was $39 \mathrm{pmol} / \mathrm{l}$ for serum and $31 \mathrm{pmol} / \mathrm{l}$ for plasma, respectively. Catecholamine levels were determined by specific ELISAs (2-Cat A-N research ELISA; Labor Diagnostika Nord) according to the manufacturer's instructions. The limit of sensitivity was $1.638 \mathrm{nmol} / 1$ for adrenaline (epinephrine) and $1.182 \mathrm{nmol} / \mathrm{l}$ for noradrenaline (norepinephrine). All measurements were carried out in duplicate, except for glucose determinations, which were done in triplicate.

RNA extraction and reverse transcription Pineal glands were snap-frozen in liquid nitrogen immediately after animals were killed and stored until extraction at $-80^{\circ} \mathrm{C}$. To extract total RNA from the pineal organs, single frozen glands were directly submerged in the extraction reagent and homogenised by vigorous pipetting. Total RNA extraction then proceeded using a Trizol-based extraction technique according to the manufacturer's instructions (PEQLAB Biotechnologie, Erlangen, Germany). RNA concentrations were determined by spectrophotometry at $260 \mathrm{~nm}$ and total RNA quality was assessed by electrophoresis on $1.3 \%$ (wt $/ \mathrm{vol}$.) denaturising formaldehyde agarose gels. For elimination of residual DNA, the RNA was subsequently subjected to DNase 1 digestion (25 min at $37^{\circ} \mathrm{C}$ ) using a kit (DNA-free; Ambion Inc., Austin, TX, USA). Total RNA $(1 \mu \mathrm{g})$ was reverse-transcribed using a kit (Promega, Madison, WI, USA) according to the manufacturer's protocols.

Real-time RT-PCR For real-time RT-PCR, 40 ng cDNA was used per reaction. Primers and sequences are listed in electronic supplementary material (ESM) Table 1. Each reaction volume of $20 \mu \mathrm{l}$ contained $10 \mu \mathrm{l}$ reaction mix (Promega), $0.5 \mu \mathrm{l}$ of each primer $(25 \mu \mathrm{mol} / 1), 0.5 \mu \mathrm{l}$ fluorescent dye (EvaGreen; Biotium, Hayward, CA, USA) and $4.5 \mu \mathrm{H}_{2} \mathrm{O}$. PCR was performed using a rotor-cycler
(Rotor-Gene 6000; Corbett Research, Mortlake, NSW, Australia) and the following thermo profile: initial denaturation at $95^{\circ} \mathrm{C}$ for $120 \mathrm{~s}$, followed by 40 cycles with $30 \mathrm{~s}$ denaturation at $94^{\circ} \mathrm{C}, 30 \mathrm{~s}$ annealing at $59^{\circ} \mathrm{C}$ (touchdown from $64^{\circ} \mathrm{C}$ with a $1{ }^{\circ} \mathrm{C}$ decrease per cycle) and $30 \mathrm{~s}$ elongation at $72^{\circ} \mathrm{C}$. At the end of each elongation step, fluorescence was determined for $15 \mathrm{~s}$ at a temperature of $80^{\circ} \mathrm{C}$. For amplicon analysis a thermal denaturation profile was generated after each run. The PCR products were further analysed by separation on TAE-buffered 3\% (wt/vol.) agarose gels $(\mathrm{pH} 8.0)$ and subsequent ethidium bromide staining, as well as by restriction analysis. Quantification of mRNA was done with Corbett Research software, comparing fluorescence intensities at a threshold level $\left(\mathrm{C}_{\mathrm{t}}\right.$-values) within the logarithmic range of the amplification curve, as previously described [31]. $\beta$-Actin expression was used for normalisation of target gene values throughout the experiments. Efficiency was calculated for each primer set from runs with serial tenfold cDNA dilutions using Corbett Research software [10]. Reaction efficiency was between 0.80 and 0.92 for target gene amplification, and 0.82 for the housekeeping gene $\beta$-actin. There was no significant variation in the levels of $\beta$-actin mRNA in the pineal gland regarding a specific time of the day in accordance with observations of Damiola et al. [32] for the mouse brain and liver. Control PCRs were performed using a PCR-reaction mix including primers without cDNA (non-template control) or with $1 \mu \mathrm{g}$ total RNA in the reaction mixture (control for DNA carryover).

Statistical analyses For statistical evaluation of results and significance testing of group differences, the nonparametric Mann-Whitney $U$ test and one-way ANOVA test were performed using GraphPad software (GraphPad Software, La Jolla, CA, USA). Groups were considered to be significantly different at $p<0.05$ (95\% CI). Data are presented as means \pm SEM of at least five animals per group unless otherwise indicated (Table 1).

\section{Results}

To investigate the influence of metabolic disturbances on body weight, male and female controls, and diabetic as well as insulin-treated diabetic rats were studied (Table 1). The results of male and female rats showed similar results in quality. The body weight of diabetic rats was reduced ( $p<$ 0.01 ), but was normalised by insulin substitution. In general, the body weight of female rats was lower.

Figure 1 presents results of male (Fig. 1a, e, i) and female (Fig. 1c, g, k) rats with their diurnal profiles. It also portrays the mean \pm SEM of peripheral blood glucose 
Table 1 Results of the different groups and variables

\begin{tabular}{|c|c|c|c|c|c|c|c|c|c|c|c|c|}
\hline \multirow[b]{2}{*}{ Variables } & \multicolumn{6}{|l|}{ Male rats } & \multicolumn{6}{|l|}{ Female rats } \\
\hline & Controls & $n$ & Diabetic & $n$ & Diabetic + insulin & $n$ & Controls & $n$ & Diabetic & $n$ & Diabetic + insulin & $n$ \\
\hline Body weight (g) & $271 \pm 2.61$ & 72 & $229.5 \pm 3.86^{* * *}$ & 73 & $265.2 \pm 3.18^{* * *}$ & 45 & $172 \pm 1.74$ & 53 & $160.5 \pm 3.13 * * *$ & 53 & $198.2 \pm 2.90^{* * *}$ & 48 \\
\hline $\begin{array}{l}\text { Blood glucose } \\
(\mathrm{mmol} / \mathrm{l})\end{array}$ & $6.60 \pm 0.11$ & 70 & $20.93 \pm 0.36^{* * *}$ & 72 & $12.49 \pm 0.81^{* * *}$ & 44 & $5.37 \pm 0.12$ & 51 & $21.54 \pm 0.52 * * *$ & 52 & $8.50 \pm 0.89^{* * *}$ & 45 \\
\hline $\begin{array}{l}\text { Plasma insulin } \\
(\mathrm{pmol} / \mathrm{l})\end{array}$ & $83.03 \pm 6.69$ & 70 & $3.28 \pm 0.37 * * *$ & 62 & $111.68 \pm 12.38 * * *$ & 43 & $51.68 \pm 13.18$ & 52 & $7.84 \pm 3.13 * * *$ & 47 & $122.74 \pm 14.00^{* * *}$ & 47 \\
\hline $\begin{array}{l}\text { Plasma melatonin } \\
(\mathrm{pmol} / \mathrm{l})\end{array}$ & $367.77 \pm 38.09$ & 71 & $2,960.46 \pm 390.75^{* * *}$ & 69 & $481.57 \pm 60.21^{* * *}$ & 44 & $739.5 \pm 101.5$ & 49 & $1,384.33 \pm 235.89 *$ & 49 & $352.17 \pm 45.71 * * *$ & 46 \\
\hline Aanat $^{\mathrm{a}}$ & $0.13 \pm 0.03$ & 38 & $0.12 \pm 0.02^{\mathrm{b}}$ & 39 & $0.25 \pm 0.04^{\mathrm{c}}$ & 43 & $0.09 \pm 0.02$ & 40 & $0.26 \pm 0.08^{\mathrm{d}}$ & 39 & $0.07 \pm 0.02^{\mathrm{e}}$ & 47 \\
\hline Hiomt $^{\mathrm{a}}$ & $0.46 \pm 0.05$ & 40 & $0.60 \pm 0.06^{\mathrm{f}}$ & 39 & $0.63 \pm 0.05^{\mathrm{g}}$ & 45 & $0.34 \pm 0.03$ & 40 & $0.54 \pm 0.06^{*}$ & 38 & $0.26 \pm 0.02 * * *$ & 48 \\
\hline Insr & $0.44 \pm 0.04$ & 40 & $0.59 \pm 0.04 * *$ & 39 & $0.61 \pm 0.04^{\mathrm{h}}$ & 44 & $0.27 \pm 0.01$ & 39 & $0.61 \pm 0.05^{* * *}$ & 44 & $0.25 \pm 0.01 * * *$ & 47 \\
\hline Adrenoceptor $\beta 1^{\mathrm{a}}$ & $0.58 \pm 0.07$ & 40 & $0.93 \pm 0.12 *$ & 40 & $0.74 \pm 0.07^{\mathrm{i}}$ & 45 & $0.19 \pm 0.02$ & 39 & $0.50 \pm 0.05 * * *$ & 45 & $0.23 \pm 0.01 * * *$ & 48 \\
\hline $\operatorname{Perl} I^{\mathrm{a}}$ & $0.15 \pm 0.02$ & 38 & $0.27 \pm 0.08 * *$ & 39 & $0.23 \pm 0.03^{j}$ & 43 & $0.17 \pm 0.03$ & 40 & $0.42 \pm 0.08^{* * *}$ & 47 & $0.17 \pm 0.02 * * *$ & 46 \\
\hline Bmall $^{\mathrm{a}}$ & $1.20 \pm 0.19$ & 43 & $1.14 \pm 0.12^{\mathrm{k}}$ & 42 & $1.32 \pm 0.17^{1}$ & 43 & $1.08 \pm 0.10$ & 39 & $2.30 \pm 0.30 * * *$ & 44 & $1.06 \pm 0.11^{* * *}$ & 48 \\
\hline
\end{tabular}

Values are mean \pm SEM (analysed by Mann-Whitney $U$ test; $n$ samples per group)

Statistically significant differences were found between control and diabetic rats, and between diabetic and insulin-substituted diabetic rats; ${ }^{*} p<0.05$; $* * p<0.01 ; * * * p<0.001$

${ }^{\mathrm{a}}$ Relative expression; ${ }^{\mathrm{b}} \mathrm{NS}(p=0.389) ;{ }^{\mathrm{c}} \mathrm{NS}(p=0.249) ;{ }^{\mathrm{d}} \mathrm{NS}(p=0.298) ;{ }^{\mathrm{e}} \mathrm{NS}(p=0.222) ;{ }^{\mathrm{f}} \mathrm{NS}(p=0.106) ;{ }^{\mathrm{g}} \mathrm{NS}(p=0.280) ;{ }^{\mathrm{h}} \mathrm{NS}(p=0.702) ;{ }^{\mathrm{i}} \mathrm{NS}(p=0.898) ;$ ${ }^{\mathrm{j}} \mathrm{NS}(p=0.900) ;{ }^{\mathrm{k}} \mathrm{NS}(p=0.401) ;{ }^{1} \mathrm{NS}(p=0.923)$

(Fig. 1b, d), plasma insulin (Fig. 1f, h) and plasma melatonin (Fig. 1j, 1). Results of male and female rats were comparable. Blood glucose levels of male and female rats showed a drastic elevation compared with those of controls, whereas insulin substitution through continuous release from implanted insulin pellets reduced glucose to levels comparable with controls. The results of plasma insulin determination in males (Fig. 1e, f) and females (Fig. 1g, h) demonstrate a drastic reduction in diabetic rats, whereas insulin substitution virtually normalised the levels compared with controls. The plasma melatonin levels (Fig. 1i-l) in diabetic rats were increased; however, they were almost normalised through insulin substitution. Very impressive is the opposite course of plasma insulin and plasma melatonin throughout a circadian period in male (Fig. 1e, i) and female rats (Fig. 1g, k). The statistically significant differences of the diurnal profiles of plasma melatonin in male and female rats as tested by one-way ANOVA were maintained in diabetic as well as insulinsubstituted rats. However, this phenomenon was not observed in the case of plasma insulin, where only the control rats displayed statistically significant diurnal profiles. The results of the three variables in Fig. 1 are of crucial importance.

To explain the data obtained, it was important to investigate the circadian expression profiles of the key enzymes of melatonin synthesis, Aanat (Fig. 2a, c) and Hiomt (also known as Asmt) (Fig. 2e, g), as well as expression of the insulin receptor (Fig. 2i, k) and adrenoceptor $\beta 1$ (Fig. 3a, c) on a transcriptional level in the pineal gland of male (Figs 2a, e, i, 3a) and female
(Figs 2c, g, k, 3c) rats. Whereas female diabetic rats had elevated expression of pineal Aanat (NS) and Hiomt (significant), male diabetic rats showed no such increases. Similarly to plasma melatonin levels (Fig. 1i-1), insulin substitution reduced expression of Aanat and Hiomt mRNA in female rats (Fig. 2c, d, g, h) almost to control levels, whereas these levels remained unchanged in male rats (Fig. 2a, b, e, f). On the other hand, the diurnal profiles of Aanat mRNA showed a maximum during the dark period and a minimum in the light period. The levels of pineal insulin receptor and pineal adrenoceptor $\beta 1$ of male (Figs 2i, j, 3a, b) and female (Figs 2k, 1, 3c, d) increased in diabetic rats. After insulin substitution these variables were normalised with the exception of pineal insulin receptor transcript levels in male rats (Fig. 2i, j). The plasma insulin levels in both sexes of diabetic animals (Fig. 1e-h) were extremely reduced and correspond in an inverse relationship with the pineal insulin receptor (Fig. 2i-1) and pineal adrenoceptor $\beta 1$ (Fig. 3a-d) transcripts.

The average expression levels of insulin receptor (Fig. 2j, 1) and adrenoceptor $\beta 1$ (Fig. 3b, d) were significantly increased in diabetic rats, whereas these effects, with the exception of the insulin receptor in male rats (Fig. 2j), were reduced by insulin substitution. In addition to the diurnal rhythms of clock genes Perl (Fig. 3e, g) and Bmall (also known as Arntl) (Fig. 3i, k) in male (Fig. 3e, i) and female (Fig. 3g, k) rats, expression of these antagonistic clock genes was analysed in control, diabetic and insulin-substituted diabetic groups (Fig. 3e-1). The expression of the clock genes was increased in diabetic rats (Fig. 3e-h, k, l), except for Bmall in male rats (Fig. 3i, j). 

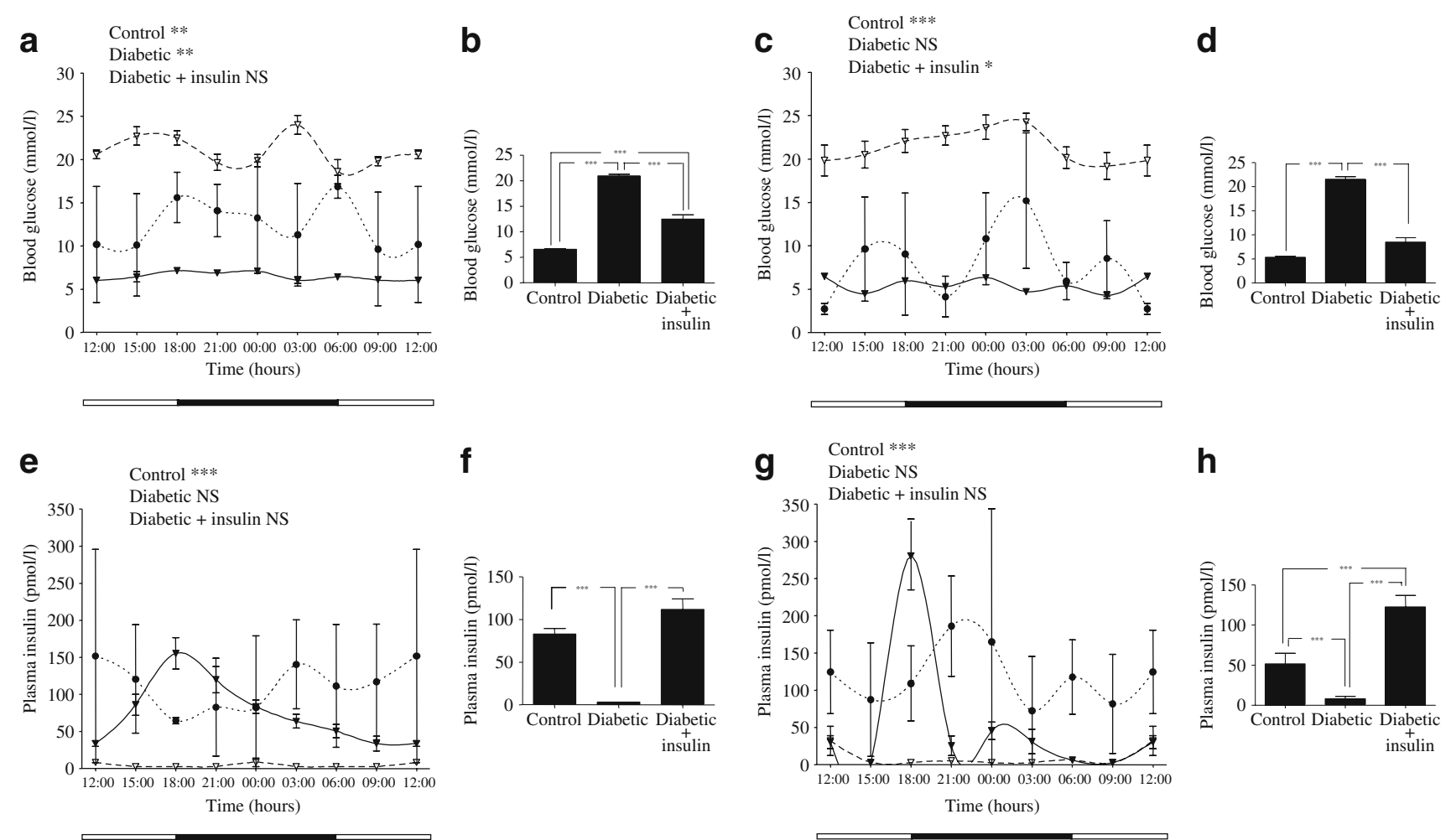

\section{h}
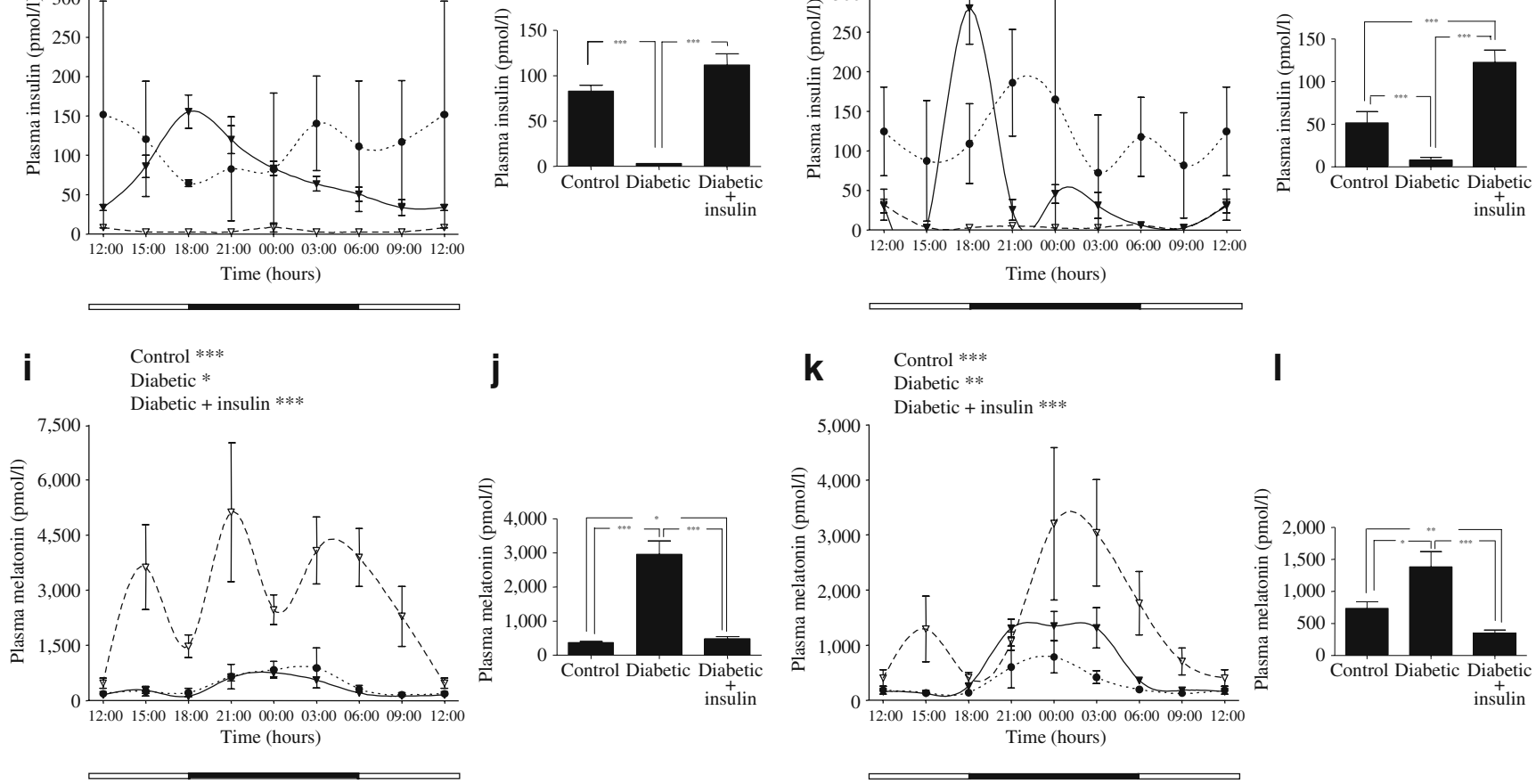

Fig. 1 Peripheral blood glucose in male $(\mathbf{a}, \mathbf{b})$ and female $(\mathbf{c}, \mathbf{d})$ rats. Plasma insulin in male $(\mathbf{e}, \mathbf{f})$ and female $(\mathbf{g}, \mathbf{h})$, and plasma melatonin in male $(\mathbf{i}, \mathbf{j})$ and female $(\mathbf{k}, \mathbf{l})$ rats. Diurnal profiles $(\mathbf{a}, \mathbf{c}, \mathbf{e}, \mathbf{g}, \mathbf{i}, \mathbf{k})$ as well as mean $\pm \operatorname{SEM}(\mathbf{b}, \mathbf{d}, \mathbf{f}, \mathbf{h}, \mathbf{j}, \mathbf{l})$ data are shown. The results show clear differences between control and diabetic rats, as well as mainly normalised data as a result of insulin substitution. The antagonistic

Insulin substitution reduced this increase to control levels. Clock genes in male and female rats, with the exception of Bmall in male rats, showed a statistically significant diurnal rhythm. The maximum of the amplitude of the inhibiting clock gene Perl was found at the beginning of the dark phase (21:00 hours) (Fig. 3e, g), whereas the activating clock gene Bmall was minimal at this time point (Fig. 3i, k).

Finally, the catecholamines adrenaline and noradrenaline were measured in blood plasma of male rats (Fig. 4). The data demonstrate that adrenaline and noradrenaline were increased in diabetic rats. The catecholamine levels

reactions between insulin and melatonin are striking. Diurnal oscillations, i.e. tests of diurnal rhythmicity, were analysed by oneway ANOVA (a, c, e, g, i, k) and mean \pm SEM by Mann-Whitney $U$ test $(\mathbf{b}, \mathbf{d}, \mathbf{f}, \mathbf{h}, \mathbf{j}, \mathbf{l}) ;{ }^{*} p<0.05, * * p<0.01,{ }^{*} * *<0.001$ The bar below $x$-axes indicates light and dark phases of diurnal period. Continuous lines, control; dashed lines, diabetic; dotted lines, diabetic +insulin

returned to near normal values after insulin substitution. In summary, the results demonstrate that the changes of the different variables in diabetic rats were normalised by insulin substitution.

\section{Discussion}

The present study deals with the influence of the diabetic metabolic state on melatonin synthesis and secretion of the pineal gland. The results emphasise the functional impor- 

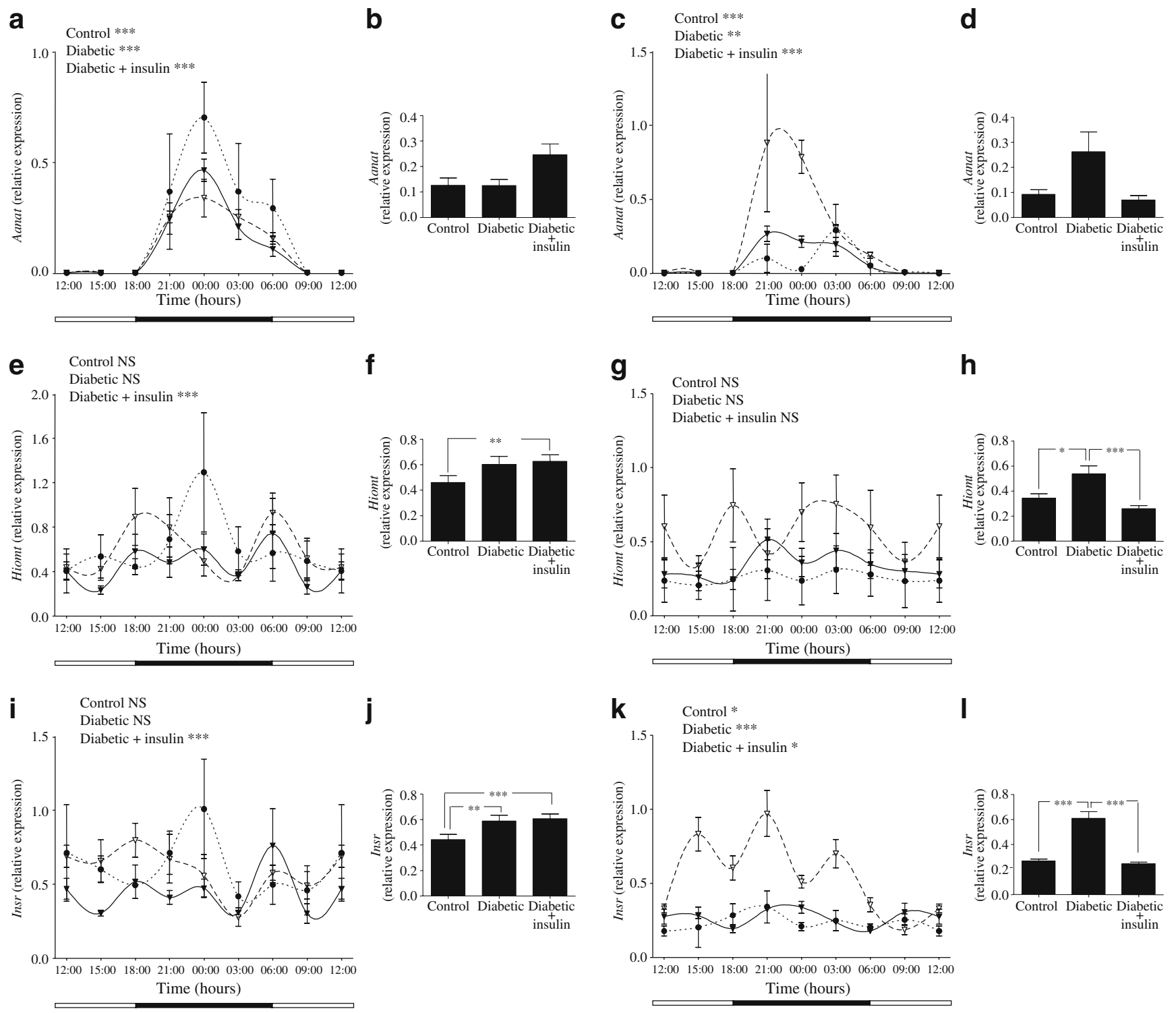

Fig. 2 Relative expression of Aanat in pineal glands of male (a, b) and female $(\mathbf{c}, \mathbf{d})$ rats. Relative expression of Hiomt in male $(\mathbf{e}, \mathbf{f})$ and female ( $\mathbf{g}, \mathbf{h})$, and of insulin receptor (Insr) in male (i, j) and female $(\mathbf{k}, \mathbf{l})$ rat pineal glands. Diurnal profiles $(\mathbf{a}, \mathbf{c}, \mathbf{e}, \mathbf{g}, \mathbf{i}, \mathbf{k})$ as well as mean $\pm \operatorname{SEM}(\mathbf{b}, \mathbf{d}, \mathbf{f}, \mathbf{h}, \mathbf{j}, \mathbf{l})$ data are shown. The results show differences between controls and diabetic rats for the expression of Hiomt and insulin receptor; however, no significant differences are

tance of the insulin-melatonin relationship and the effects of melatonin on the pancreatic beta cell $[1,3,8]$, which are mediated by $\mathrm{MT}_{1}[2,6]$ and $\mathrm{MT}_{2}[9,10]$ receptors $[8,33]$. Previous studies have established that the effect of melatonin on the pancreatic beta cell is mediated by three intracellular pathways, as described in the introduction. Recent investigations have proven that slightly elevated plasma insulin levels are coupled to decreased plasma melatonin. These conditions are fulfilled in type 2 diabetes in rats and humans $[10,17]$. In contrast, a rat model of type 1 diabetes induced by streptozotocin had either decreased shown for Aanat mRNA. Diurnal oscillations, i.e. tests of diurnal rhythmicity, were analysed by one-way $\operatorname{ANOVA}(\mathbf{a}, \mathbf{c}, \mathbf{e}, \mathbf{g}, \mathbf{i}, \mathbf{k})$; and mean \pm SEM of all the diurnal data combined by Mann-Whitney $U$ test $(\mathbf{b}, \mathbf{d}, \mathbf{f}, \mathbf{h}, \mathbf{j}, \mathbf{l}) ;{ }^{*} p<0.05,{ }^{* *} p<0.01,{ }^{* * *} p<0.001$. The bar below $x_{-}$ axes indicates light and dark phases of diurnal period. Continuous lines, control; dashed lines, diabetic; dotted lines, diabetic+insulin

or undetectable insulin levels, combined with elevated melatonin levels and increased expression of pineal Aanat, Hiomt, insulin receptor and the clock genes Per1, Bmal1, Dbp and adrenoceptor $\beta 1$ [21]. Furthermore, diabetic rats showed stable diurnal rhythms of the variables listed above. These findings suggest that the pineal gland with its enhanced synthesis of the synchronising hormone melatonin and intact circadian oscillations of Aanat, Hiomt and the clock genes can compensate for severe metabolic disturbances [34]. These results are in contrast to data of others, for example Champney et al. 

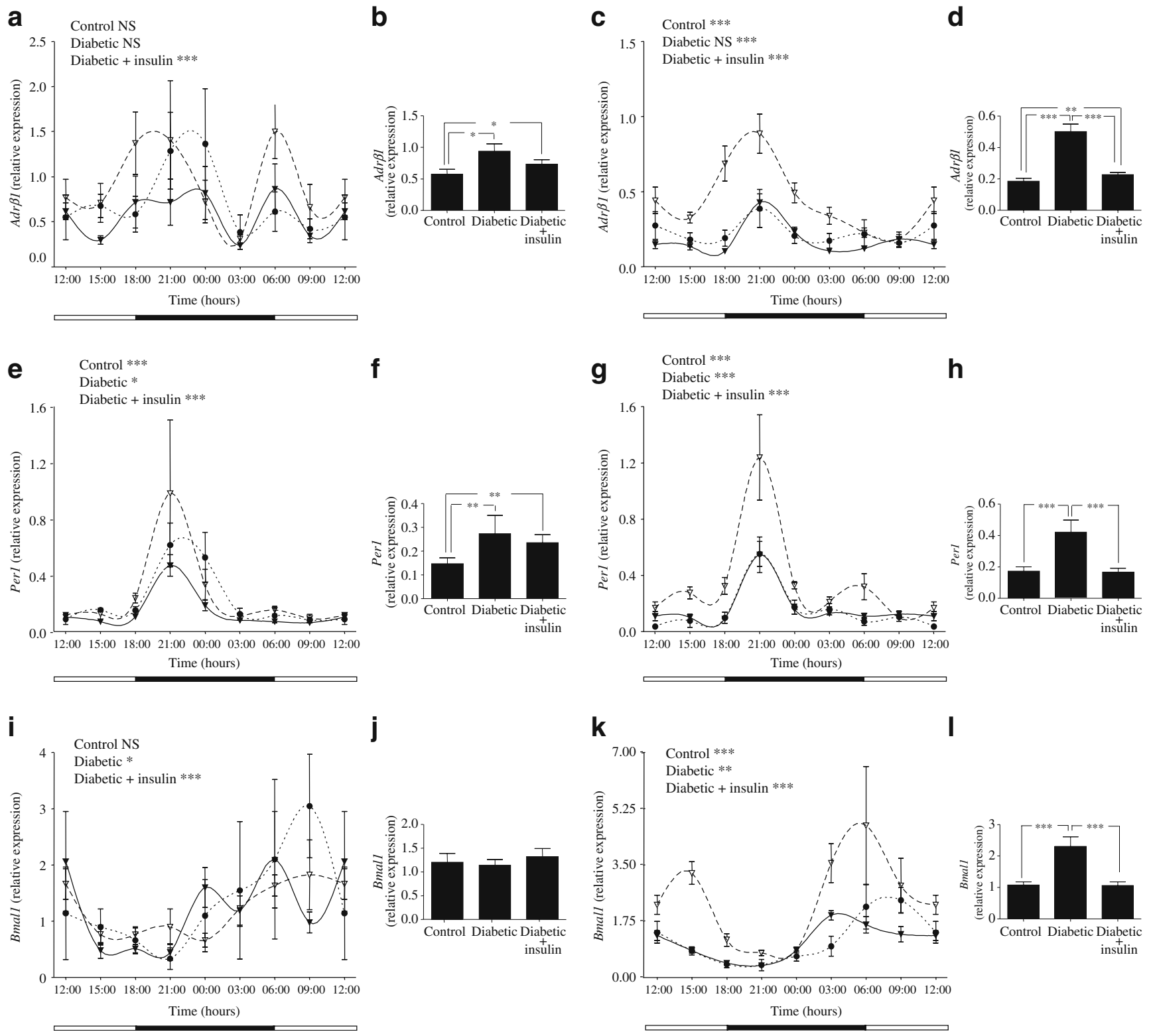

Fig. 3 Relative expression of adrenoceptor $\beta 1(A d r \beta 1)$ in male $(\mathbf{a}, \mathbf{b})$ and female $(\mathbf{c}, \mathbf{d})$ rats. Relative expression of clock genes Perl in male $(\mathbf{e}, \mathbf{f})$ and female $(\mathbf{g}, \mathbf{h})$, and Bmall in male $(\mathbf{i}, \mathbf{j})$ and female $(\mathbf{k}, \mathbf{l})$ rats. Diurnal profiles (a, c, e, $\mathbf{g}, \mathbf{i}, \mathbf{k})$ as well as mean $\pm \operatorname{SEM}(\mathbf{b}, \mathbf{d}, \mathbf{f}, \mathbf{h}, \mathbf{j}, \mathbf{l})$ data are shown. The adrenoceptor $\beta 1$ and the clock gene Perl in diabetic male and female, as well as Bmall in female diabetic rats showed a statistically significant increased expression, which was normalised in male and female rats by insulin substitution. Expression

[35, 36] and, more recently, Stebelova et al. [37]. Moreover, opposite results on diurnal variations in plasma insulin, leptin, glucocorticoids, growth and thyroid hormones, glucose and fatty acids, as well as on the sympathetic neuronal activity, have been reported by other investigators [38-41].

In view of these differing results, it was paramount to clarify the following questions. First, can it be ruled out that streptozotocin causes unspecific reactions besides its

of Bmall in male rats showed no significant differences between the three groups. Diurnal oscillations, i.e. tests of diurnal rhythmicity, were analysed by one-way ANOVA (a, $\mathbf{c}, \mathbf{e}, \mathbf{g}, \mathbf{i}, \mathbf{k})$; and mean \pm SEM of all the diurnal data combined by Mann-Whitney $U$ test $(\mathbf{b}, \mathbf{d}, \mathbf{f}, \mathbf{h}, \mathbf{j}$, l); ${ }^{*} p<0.05,{ }^{* *} p<0.01,{ }^{* * *} p<0.001$. The bar below $x$-axes indicates light and dark phases of a circadian period. Continuous lines, control; dashed lines, diabetic; dotted lines, diabetic + insulin

classical effect, namely the destruction of the pancreatic beta cells with a subsequent loss of insulin production? Second, why are melatonin levels increased in rat models of type 1 diabetes (streptozotocin-induced and LEW.1AR1$i d d m)$ ? Additionally, we wanted to investigate male as well as female LEW.1AR1-iddm rats to analyse possible sexual dimorphisms. The body weight of female rats was in general lower than that of their male counterparts. These data are in agreement with those of others, who registered 


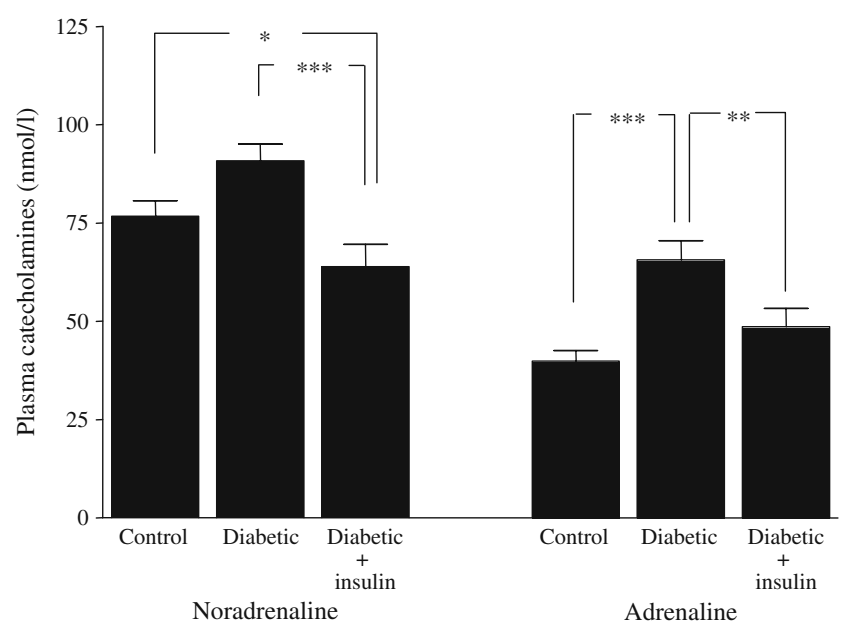

Fig. 4 Noradrenaline and adrenalin determination in male rats by ELISA, without consideration of diurnal fluctuations. Results indicate increased levels in diabetic rats compared with controls as well as normalised values in insulin-treated diabetic animals. Values are mean \pm SEM and were analysed by Mann-Whitney $U$ test; ${ }^{*} p<0.05,{ }^{* *} p<0.01$, $* * * p<0.001$

age-dependent sexual dimorphisms of weight and other variables [42]. These observations were the basis for our decision to investigate male and female rats. In general, the normalisation effects of insulin substitution on the transcript levels of the investigated genes were less clear-cut in male than in female rats. However, the crucial variables glucose, insulin and melatonin demonstrated a high concordance between the sexes. In addition, male and female LEW.1AR1-iddm rats had reduced weight in comparison with the controls. Substitution of insulin normalised the body weight. Our results also demonstrate convincingly that male and female LEW.1AR1-iddm rats had elevated blood glucose levels, combined with decreased plasma insulin and increased plasma melatonin. Insulin substitution normalised these values. These results support the existence of an insulin-melatonin antagonism, in agreement with recent data showing that long-term enteral application of melatonin reduced plasma insulin levels and increased expression of pineal insulin receptor mRNA [43]. The present study confirmed that, regardless of the extreme metabolic disturbances, the diurnal rhythms of increased plasma melatonin concentrations were conserved with expected higher levels during the dark period. In agreement with the increased level of plasma melatonin, expression of genes encoding the key enzymes of melatonin synthesis, Aanat and Hiomt, was upregulated, especially in the pineals of female rats. These data are consistent with expression results of the insulin receptor and the adrenoceptor $\beta 1$ in the pineals. The expression of both genes was increased in LEW.1AR1-iddm rats, an effect that was counteracted by insulin substitution. In contrast to the LEW.1AR1-iddm rats of the present study, expression of pineal insulin receptor mRNA was decreased in the GK rat model of type 2 diabetes, together with an increase of plasma insulin [17]. These antagonistic reactions of plasma insulin and pineal insulin receptors show that insulin apparently influences melatonin synthesis in the pineal gland of the rat. There was no functional relationship between glucose and melatonin, because high levels of glucose were measured in both animal models, i.e. of type 1 (streptozotocin, LEW.1AR1-iddm) and type 2 diabetes (GK). However low levels of insulin were combined with high levels of melatonin (streptozotocin, LEW.1AR1$i d d m$ ) and increased insulin was combined with low concentrations of melatonin (GK). We also proved that the reactions were a direct result of the metabolic changes, and not a non-specific toxic effect of a toxin like streptozotocin.

In this context it was important to demonstrate that in pinealocytes the inhibiting clock gene Perl and activating clock gene Bmall showed intact diurnal rhythms, with peaks of Perl at the beginning of the dark phase (21:00 hours) and minimum expression of Bmall at this time point. This antiphasic course of the diurnal oscillation of Perl and Bmall transcripts in the pineal gland could be expected as an expression of intact biorhythm of the animals, which was also found for certain other variables (for example plasma melatonin and Aanat mRNA) of the investigated groups.

The coincidence of increasing plasma melatonin and adrenoceptor $\beta 1$ mRNA, in conjunction with increased insulin receptor expression in the pineals together with the loss of plasma insulin, is the basis for the observed functional interactions of insulin-melatonin antagonism in our rat model of type 1 diabetes. The well-known insulinnoradrenaline relationship may be the key to the understanding of this functional correlation. This relationship is clearly evident, since the GK rat model of type 2 diabetes has diminished plasma catecholamines [44], whereas in the rat model of type 1 diabetes increased catecholamines occur in different tissues [38]; the latter model also has increased catecholamine metabolism [45] in comparison with metabolically intact rats. In contrast, different results were observed, for example by Garcia et al. [46], who report that insulin potentiated noradrenaline-mediated melatonin synthesis, as well as arylalkyl- $N$-acetyltransferase activity. It should, however, be noted that this was a report on pineal glands incubated ex vivo. In that case, the authors described that insulin did not affect the activity of hydroxyindole- $O$ methyltransferase, or expression of Aanat and Hiomt. Recently, however, the same group was able to show in an in vitro experiment [47] that insulin 'in some timedinsulin-stimulations' also promoted a reduction of melatonin synthesis, which means that insulin, in dependence of 
the time-point of the diurnal rhythm, had different influences on melatonin synthesis. The latter point is in agreement with our own in vivo results on antagonistic reactions of insulin and melatonin $[8,10,43]$, which are based on crosstalk between noradrenergic and insulin pathways in the rat pineal gland. To explain the results of the present study, it is important to emphasise the strong insulin decrease combined with activation of pineal melatonin synthesis and secretion. This activation of the adrenoceptor $\beta 1$, as demonstrated in this study, is combined with the well-known increase of noradrenaline content [38] and catecholamine metabolism [45]. This effect is likely to be due to a decrease in catechol- $O$-methyltransferase activity in a rat model of type 1 diabetes when stressed [48]. We were able to confirm these results in our rat model of type 1 diabetes. In agreement with the hypothesis described above of a functional relationship between catecholamines and insulin, we observed normalisation of catecholamines due to insulin treatment. This indicates that the treatment also normalised noradrenaline turnover, an index of sympathetic nerve activity. In summary, the increase of catecholamines stimulates adrenoceptor $\beta 1$ and consequently the cAMP cascade, as well as adrenoceptor $\alpha 1$, which activates the $\mathrm{IP}_{3}$ cascade in the pineal gland and subsequently melatonin synthesis and secretion $[8,18,44]$. An explanation of the increased melatonin levels in our rat models of type 1 diabetes (streptozotocin and LEW.1AR1-iddm) could be that the melatonin increase is a protective reaction of the organism, as reviewed by others [49], to counteract diabetes-induced stress, thereby attenuating oxidative stress-induced beta cell damage in type 1 diabetes, as previously suggested in a review [50]. It cannot be ruled out that the high level of melatonin in our rat model of an autoimmune disease may be a defence response to suppress the rapid progress of islet and beta cell destruction. However, it should be kept in mind that also a similar enhancement of melatonin was also monitored in a streptozotocin-treated rat model of type 1 diabetes [21].

Acknowledgements The authors thank B. Heydel for skilful technical assistance and E. Axmann for linguistic help with the manuscript. This study was supported by a grant from Deutsche Diabetes-Stiftung, Germany.

Duality of interest The authors declare that there is no duality of interest associated with this manuscript.

\section{References}

1. Peschke E, Peschke D, Hammer T, Csernus V (1997) Influence of melatonin and serotonin on glucose-stimulated insulin release from perifused rat pancreatic islets in vitro. J Pineal Res 23:156163
2. Peschke E, Muhlbauer E, Musshoff U, Csernus VJ, Chankiewitz E, Peschke D (2002) Receptor (MT(1)) mediated influence of melatonin on cAMP concentration and insulin secretion of rat insulinoma cells INS-1. J Pineal Res 33:63-71

3. Picinato MC, Haber EP, Cipolla-Neto J, Curi R, de Oliveira Carvalho CR, Carpinelli AR (2002) Melatonin inhibits insulin secretion and decreases PKA levels without interfering with glucose metabolism in rat pancreatic islets. J Pineal Res 33:156160

4. Reppert SM, Weaver DR, Ebisawa T (1994) Cloning and characterization of a mammalian melatonin receptor that mediates reproductive and circadian responses. Neuron 13:1177-1185

5. Reppert SM, Godson C, Mahle CD, Weaver DR, Slaugenhaupt SA, Gusella JF (1995) Molecular characterization of a second melatonin receptor expressed in human retina and brain: the Mellb melatonin receptor. Proc Natl Acad Sci USA 92:87348738

6. Peschke E, Fauteck JD, Musshoff U, Schmidt F, Beckmann A, Peschke D (2000) Evidence for a melatonin receptor within pancreatic islets of neonate rats: functional, autoradiographic, and molecular investigations. J Pineal Res 28:156-164

7. Kemp DM, Ubeda M, Habener JF (2002) Identification and functional characterization of melatonin Mel 1a receptors in pancreatic beta cells: potential role in incretin-mediated cell function by sensitization of cAMP signaling. Mol Cell Endocrinol 191:157-166

8. Peschke E (2008) Melatonin, endocrine pancreas and diabetes. J Pineal Res 44:26-40

9. Muhlbauer E, Peschke E (2007) Evidence for the expression of both the MT1- and in addition, the MT2-melatonin receptor, in the rat pancreas, islet and beta-cell. J Pineal Res 42:105-106

10. Peschke E, Stumpf I, Bazwinsky I, Litvak L, Dralle H, Muhlbauer E (2007) Melatonin and type 2 diabetes - a possible link? J Pineal Res 42:350-358

11. Ramracheya RD, Muller DS, Squires PE et al (2008) Function and expression of melatonin receptors on human pancreatic islets. J Pineal Res 44:273-279

12. Peschke E, Bach AG, Muhlbauer E (2006) Parallel signaling pathways of melatonin in the pancreatic beta-cell. J Pineal Res 40:184-191

13. Bach AG, Wolgast S, Muhlbauer E, Peschke E (2005) Melatonin stimulates inositol-1,4,5-trisphosphate and $\mathrm{Ca} 2+$ release from INS1 insulinoma cells. J Pineal Res 39:316-323

14. Stumpf I, Muhlbauer E, Peschke E (2008) Involvement of the cGMP pathway in mediating the insulin-inhibitory effect of melatonin in pancreatic beta-cells. J Pineal Res 45:318-327

15. Stumpf I, Bazwinsky I, Peschke E (2009) Modulation of the cGMP signaling pathway by melatonin in pancreatic beta-cells. $\mathrm{J}$ Pineal Res 46:140-147

16. Goto Y, Suzuki K, Ono T, Sasaki M, Toyota T (1988) Development of diabetes in the non-obese NIDDM rat (GK rat). Adv Exp Med Biol 246:29-31

17. Peschke E, Frese T, Chankiewitz E et al (2006) Diabetic Goto Kakizaki rats as well as type 2 diabetic patients show a decreased diurnal serum melatonin level and an increased pancreatic melatonin-receptor status. J Pineal Res 40:135-143

18. Frese T, Bach AG, Muhlbauer E et al (2009) Pineal melatonin synthesis is decreased in type 2 diabetic Goto-Kakizaki rats. Life Sci 85:526-533

19. Tutuncu NB, Batur MK, Yildirir A et al (2005) Melatonin levels decrease in type 2 diabetic patients with cardiac autonomic neuropathy. J Pineal Res 39:43-49

20. Bach AG, Mühlbauer E, Peschke E (2010) Adrenoceptor expression and diurnal rhythms of melatonin and its precursors in the pineal gland of type 2 diabetic Goto-Kakizaki rats. Endocrinology 151:2483-2493 
21. Peschke E, Wolgast S, Bazwinsky I, Ponicke K, Muhlbauer E (2008) Increased melatonin synthesis in pineal glands of rats in streptozotocin induced type 1 diabetes. J Pineal Res 45:439448

22. Nishida S, Segawa T, Murai I, Nakagawa S (2002) Long-term melatonin administration reduces hyperinsulinemia and improves the altered fatty-acid compositions in type 2 diabetic rats via the restoration of Delta-5 desaturase activity. J Pineal Res 32:26-33

23. Nishida S (2005) Metabolic effects of melatonin on oxidative stress and diabetes mellitus. Endocrine 27:131-136

24. Wolden-Hanson T, Mitton DR, McCants RL et al (2000) Daily melatonin administration to middle-aged male rats suppresses body weight, intraabdominal adiposity, and plasma leptin and insulin independent of food intake and total body fat. Endocrinology 141:487-497

25. Rasmussen DD, Boldt BM, Wilkinson CW, Yellon SM, Matsumoto AM (1999) Daily melatonin administration at middle age suppresses male rat visceral fat, plasma leptin, and plasma insulin to youthful levels. Endocrinology 140:1009-1012

26. Bojkova B, Orendas P, Friedmanova L et al (2008) Prolonged melatonin administration in 6-month-old Sprague-Dawley rats: metabolic alterations. Acta Physiol Hung 95:65-76

27. Cagnacci A, Arangino S, Renzi A et al (2001) Influence of melatonin administration on glucose tolerance and insulin sensitivity of postmenopausal women. Clin Endocrinol Oxf 54:339-346

28. Nishida S, Sato R, Murai I, Nakagawa S (2003) Effect of pinealectomy on plasma levels of insulin and leptin and on hepatic lipids in type 2 diabetic rats. J Pineal Res 35:251-256

29. Rodriguez V, Mellado C, Alvarez E, de Diego JG, Blazquez E (1989) Effect of pinealectomy on liver insulin and glucagon receptor concentrations in the rat. J Pineal Res 6:77-88

30. Lenzen S, Tiedge M, Elsner M et al (2001) The LEW.1AR1/Zmt$i d d m$ rat: a new model of spontaneous insulin-dependent diabetes mellitus. Diabetologia 44:1189-1196

31. Mühlbauer E, Wolgast S, Finckh U, Peschke D, Peschke E (2004) Indication of circadian oscillations in the rat pancreas. FEBS Lett 564:91-96

32. Damiola F, Le Minh N, Preitner N, Kornmann B, Fleury-Olela F, Schibler U (2000) Restricted feeding uncouples circadian oscillators in peripheral tissues from the central pacemaker in the suprachiasmatic nucleus. Genes Dev 14:2950-2961

33. Mulder H, Nagorny CL, Lyssenko V, Groop L (2009) Melatonin receptors in pancreatic islets: good morning to a novel type 2 diabetes gene. Diabetologia 52:1240-1249

34. Yavuz O, Cam M, Bukan N, Guven A, Silan F (2003) Protective effect of melatonin on beta-cell damage in streptozotocin-induced diabetes in rats. Acta Histochem 105:261-266

35. Champney TH, Brainard GC, Richardson BA, Reiter RJ (1983) Experimentally-induced diabetes reduces nocturnal pineal melatonin content in the Syrian hamster. Comp Biochem Physiol A Comp Physiol 76:199-201
36. Champney TH, Holtorf AP, Craft CM, Reiter RJ (1986) Hormonal modulation of pineal melatonin synthesis in rats and Syrian hamsters: effects of streptozotocin-induced diabetes and insulin injections. Comp Biochem Physiol A Comp Physiol 83:391-395

37. Stebelova K, Herichova I, Zeman M (2007) Diabetes induces changes in melatonin concentrations in peripheral tissues of rat. Neuro Endocrinol Lett 28:159-165

38. Ostenson CG, Hjemdahl P, Efendic S (1993) Release of catecholamines is increased but does not contribute to the impaired insulin secretion in the perfused pancreata of diabetic rats. Pancreas 8:34 38

39. Bernardi L, Ricordi L, Lazzari P et al (1992) Impaired circadian modulation of sympathovagal activity in diabetes. A possible explanation for altered temporal onset of cardiovascular disease. Circulation 86:1443-1452

40. Hicks KK, Seifen E, Stimers JR, Kennedy RH (1998) Effects of streptozotocin-induced diabetes on heart rate, blood pressure and cardiac autonomic nervous control. J Auton Nerv Syst 69:21-30

41. Velasco A, Huerta I, Marin B (1988) Plasma corticosterone, motor activity and metabolic circadian patterns in streptozotocin-induced diabetic rats. Chronobiol Int 5:127-135

42. Vital P, Larrieta E, Hiriart M (2006) Sexual dimorphism in insulin sensitivity and susceptibility to develop diabetes in rats. J Endocrinol 190:425-432

43. Peschke E, Schucht H, Mühlbauer E (2010) Long-term enteral administration of melatonin reduces plasma insulin and increases expression of pineal insulin receptors in both Wistar and type 2diabetic Goto-Kakizaki rats. J Pineal Res 49:373-381

44. Peschke E, Mühlbauer E (2007) Funktionelle Beziehungen zwischen Melatonin und Insulin-Untersuchungsergebnisse an stoffwechselgesunden und diabetischen Versuchstieren und Patienten. In: Peschke E (ed.) Endokrinologie III. Vorträge im Rahmen des Projektes 'Zeitstrukturen endokriner Systeme'. Abh Sächs Akad Wiss Leipzig 64:103-118 (in German)

45. Bitar MS, Koulu M, Rapoport SI, Linnoila M (1987) Adrenal catecholamine metabolism and myocardial adrenergic receptors in streptozotocin diabetic rats. Biochem Pharmacol 36:10111016

46. Garcia RA, Afeche SC, Scialfa JH et al (2008) Insulin modulates norepinephrine-mediated melatonin synthesis in cultured rat pineal gland. Life Sci 82:108-114

47. Peliciari-Garcia RA, Marcal AC, Silva JA et al (2010) Insulin temporal sensitivity and its signaling pathway in the rat pineal gland. Life Sci 87:169-174

48. Wang JP, Liu IM, Tzeng TF, Cheng JT (2002) Decrease in catecholO-methyltransferase activity in the liver of streptozotocin-induced diabetic rats. Clin Exp Pharmacol Physiol 29:419-422

49. Reiter RJ, Paredes SD, Manchester LC, Tan DX (2009) Reducing oxidative/nitrosative stress: a newly-discovered genre for melatonin. Crit Rev Biochem Mol Biol 44:175-200

50. Lenzen S (2008) Oxidative stress: the vulnerable beta cell. Biochem Soc Trans 36:343-347 